\title{
A comparative study of Life Satisfaction and Resilience amongst parents who live with their married children and who do not live with their married children
}

\author{
Radhika Nitin Mehendale ${ }^{1}$, Jennifer Chandnani ${ }^{2}$, Archana Patki ${ }^{3}$ \\ ${ }^{1}$ Postgraduate student, Department of Psychology, Smt Maniben M.P. Shah Women's College Of Arts \&Commerce, \\ Matunga, Mumbai. \\ ${ }^{2}$ Assistant Professor, Department of Psychology, Smt Maniben M.P. Shah Women's College Of Arts \&Commerce, \\ Matunga, Mumbai. \\ ${ }^{3}$ Head, Department of Psychology, Smt Maniben M.P. Shah Women's College Of Arts \&Commerce, Matunga, \\ Mumbai.
}

\begin{abstract}
Background: Life Satisfaction and Resilience among parents with respect to the Family Type they are living in, that is; either with their married children (Joint Family) or not with their married children (Nuclear family) is not very different. Life Satisfaction can be a key construct to understand successful ageing. It is defined as person's overall life with specific aspects such as family, friends, and community. Resilient older adults are found to be able to bounce back from adversities and they try to re-integrate themselves. The aim of the study was to study differences between these two groups.

Methodology: For this study, 50 couples in each group were given Life Satisfaction scale and Resilience scale. The participants' age range was from 55 to 75 years of age. The sample obtained was through the purposive sampling which is a non probability sampling strategy. Gender was not a matter of constraint in the study and both males and females were allowed to be a part of the study as both husband and wife were included as parents. To analyze the data, a t-test of independent samples was computed.

Results: The mean score of Life Satisfaction was found to be $54.82(\mathrm{SD}=5.623)$ in Joint Families and $52.62(\mathrm{SD}=9.827)$ in Nuclear Families. The mean score of Resilience was found to be $156.30(\mathrm{SD}=$ 14.604) in Joint Families and $155.64(\mathrm{SD}=18.973)$ in Nuclear families. A t- Test was conducted to help to understand if there were any significant differences between the means of Life Satisfaction and Resilience among parents living with their married children and not living with their married children which was found to be not significant at 0.05 level.

Conclusions: The results of the present study found no significant difference in Life Satisfaction and Resilience among parents with respect to Family Type that they were living in, that is; either with their married children (Joint Family) or not with their married children (Nuclear Family).
\end{abstract}

Key Words: Family Type, Life Satisfaction, Resilience, Parents, married, unmarried.

(Paper received $-11^{\text {th }}$ May 2016, Peer review completed $-4^{\text {th }}$ Sept 2016, Accepted $-6^{\text {th }}$ October 2016)

\section{INTRODUCTION}

In India, the notion of kinship ties for support through the life course is central to everyday life. It stipulates that it is the duty of a child- particularly a male child- to provide parental support in their old age, traditionally in the form of co residence. Even in the case of female child girls are usually expected to look after their parents as they are expected to behave in a responsible manner. Elderly parents co-residing with their children can serve a dual purpose: children can take care of their parents' health and daily needs, while parents can provide childcare for young grandchildren. These are non-financial aspects of co residence that typify a joint living arrangement. Other benefits include those to elder health, particularly in 
terms of the relationship between co-residence and self-rated health, chronic and short-term morbidity [1]. Additionally, multigenerational households allow a pooling of finances and resources. This can either relieve the household budget constraint in case of strong pension systems, or exacerbate poverty when most financial support flow is upwards. For elders that live alone, this financial safety net can disappear, adding a potential poverty dimension to ageing in India [2].

Prior research has indicated that life satisfaction is a key construct for understanding successful aging and has identified five potential determinants of the life satisfaction of elderly: three key dispositional variables (i.e., self-esteem, relationship harmony, and optimism) and perceptions relative to the two key problems associated with old age (i.e., health and financial status).

Psychological life satisfaction is a robust predictor of wellbeing. In essence, life satisfaction is a subjective assessment of the quality of one's life, because it is inherently an evaluation judgment of life satisfaction. Life satisfaction has been defined as a cognitive evaluation of the quality of a person's overall life or with specific aspect of life such as family, friends and community [3]. In terms of resilience, resilient older adults are able to adjust to life adversities with little disruption to their lives. Resilience is considered a personality characteristic that moderates the negative effects of stress and promotes adaptation [4]. As people age they often encounter challenges such as the development of chronic illness and the emotional stress resulting from the loss of loved ones. According to the Resiliency model [5], if individuals experience disruption to their lives when a stressor is encountered, they rely on internal protective factors, such as selfreliance and good health, as well as external protective factors, such as social networks, to restore balance in their lives. This process is referred to as resilient reintegration.

\section{Life Satisfaction}

Psychological life satisfaction is a robust predictor of wellbeing. Satisfaction is a Latin word that means to make or do enough. Satisfaction with one's life implies contentment with or acceptances or the fulfillment of one's wants and needs for one's life as a whole. In essence, life satisfaction is a subjective assessment of the quality of one's life, because it is inherently an evaluation judgment of life satisfaction. Life satisfaction has a large cognitive component [6]. Accordingly to the individual's overall life satisfaction reports are based upon personal comparisons between self determined criteria and perceived life circumstances. Similarly, life satisfaction refers to a person's subjective evaluation of the degree to which his/her most important needs, goals and wishes have been fulfilled [7]. Life satisfaction is used with a number of related concepts. Life satisfaction has been defined as a cognitive evaluation of the quality of a person's overall life or with specific aspect of life such as family, friends and community [3].

\section{Theories of Life Satisfaction}

Life satisfaction is relative: According to Veenhoven [8] this theory evaluate life assumes that satisfaction is the result of a comparison between life-as-it-is to conceptions of how-life-should-be. Standards of howlife-should-be are seen to draw on perceptions of what is feasible and on comparison with others.

Life satisfaction is a trait: This theory suggests that the hope of creating greater happiness for the greater number is futile, holds that satisfaction is a fixed disposition. This theory figures at the individual level as well as the societal level.

\section{Resilience}

Resilience is an "inner strength" that helps you bounce back after stressful situations. When you are resilient, you may recover more quickly from setbacks or difficult changes, including illness. Resilience is conceptualized as a global term that refers to a process by which people bounce back from adversity and reintegrate and ideally grow from the experience. Resilience develops and changes over time through ongoing experiences. Resilience is the capacity to withstand stress and catastrophe. Psychologists have long recognized the capabilities of humans to adapt and overcome risk and adversity. Individuals and communities are able to rebuild their lives even after devastating tragedies. Being resilient doesn't mean going through life without experiencing stress and pain. People feel grief, sadness, and a range of other emotions after adversity and loss. The road to resilience lies in working through the emotions and effects of stress and painful events. Resilience is also not something that you're either born with or not. Resilience 
develops as people grow up and gain better thinking and self-management skills and more knowledge [910]. Resilience simply stated, is positive adaptation in response to adversity [11]. Resilience in psychology refers to the idea of an individual's ability to cope with stress and adversity. This coping may result in the individual "bouncing back" to a previous state of normal functioning, or experience the exposure of adversity to produce a "steeling effect" and function better than expected. Resilience can indicate a capacity to resist a sharp decline in functioning even though a person temporarily appears to get worse [12].

Studies of aging process also show people's Resilience in response to life challenges. Contrary to popular belief, most people over the age 65 are not ill- health, are not lonely, and are not suffering from depression. In fact, ratings of life satisfaction and self-esteem are, on average, as high in old age as in any other period of adulthood.

\section{METHODOLOGY}

The present study samples a population of parents (middle aged and old aged) within 55 to 75 years of age range. Gender was not a matter of constraint in the study and both males and females were allowed to be a part of the study as both husband and wife were included as parents. The sample obtained was through the purposive sampling which is a non probability sampling strategy. The study is predominantly explanatory in nature since it explains the causal relationship between parents living with married children (Joint Family) and parents not living with their married children (Nuclear Family).

Tools for the study: The following scales were administered for the purpose of this study. Both the groups were assessed on the following outcomes measures.

1. The Satisfaction with Life Scale (SWLS) - The Satisfaction with Life Scale (SWLS) is a measure of life satisfaction developed by Diener, Emmons, and Larsen \& Griffin. Life satisfaction is distinguished from affective appraisal in that it is more cognitively than emotionally driven. Life satisfaction can be assessed specific to a particular domain of life (e.g., work, family) or globally. The SWLS is a global measure of life satisfaction. It is based on the 5 point scales. The 5 point scales assesses the degree of agreement or disagreement of the individual. It is comprised on the 5 items. The score range from $31-35$ high score which denote the extremely satisfied, 5 - 9score range is low score denote the extremely dissatisfied [13]. Life satisfaction may be defined as a conscious, cognitive, global judgment of one's own life. Pavot and Diener [14] reported test retest reliability ranging $0.83-0.50$ - intervals ranged from 2 weeks to 4 years and, in general, higher reliabilities were associated with shorter retest intervals.

2. The 14 Item Resilience Scale - The 12 item Resilience Scale is a measure developed by Young and Wagnild [15]. The original version consists of 25 items and the shorter version consists of 14 items which is being used in the present research. A short version of the RS (RS-14) was developed to provide clinicians and researchers a shorter instrument to reduce participant's burden. The RS-14 consists of 14 items selected from the original RS. The internal consistency of the RS-14 has been reported to be excellent $(\alpha=.93)$ and it correlates strongly $(r=.97)$ with the original RS . The factor analysis of the RS-14 resulted in one strong factor solution which was also found in a later study [16]. The RS-14 has shown similar negative correlations with depression and anxiety and positive correlations with self-actualization and stress management as the original RS.

\section{STATISTICAL ANALYSIS}

The data was collected manually within the 3 months period. Participants were verbally informed of the time period within which the tests needed to be returned. After administration of the test, the raw scores were obtained. Thereafter, the appropriate scoring procedures for both tests were followed in order to obtain an accurate total score for each of the test that is 'Satisfaction with Life Scale' and '14 RS Resilience Scale'. Further analysis of the data collected involved the use of Inferential Statistics. Student's T- Test was 
the statistic of choice since there is one independent variable with two levels and two dependent variables. T-Test was computed by using student version of SPSS.

\section{RESULTS}

Table No.1 shows mean and standard deviation among Life Satisfaction and Resilience among parents who live with their married children (Joint family) and parents who do not live with their married children (Nuclear family). The mean differences are found in both groups

Table 1

\begin{tabular}{|cccccc|}
\hline Construct & & & & & \\
& FT & N & Mean & St. Deviation & St. Error Mean \\
\hline Life Satisfaction & J & 50 & 54.48 & 5.623 & 0.795 \\
\hline & N & 50 & 52.62 & 9.827 & 1.390 \\
\hline & & & & & \\
\hline Resilience & J & 50 & 156.30 & 14.604 & 2.065 \\
\hline & N & 50 & 155.64 & 18.973 & 2.683 \\
\hline
\end{tabular}

The mean score of Life Satisfaction was found to be 54.82 in Joint Families and 52.62 in Nuclear Families. The mean score of Resilience was found to be 156.30 in Joint Families and 155.64 in Nuclear families. The standard deviation was obtained 5.623 in Joint Families whereas in Nuclear Families it was found to be 9.827. The standard deviation was obtained in 14.604 in Joint Families whereas in Nuclear Families it was found to be 18.973 .

Table 2 - t-test value

\begin{tabular}{|c|c|c|c|c|c|}
\hline $\begin{array}{l}\text { Levene's Test for } \\
\text { Equality of Variances }\end{array}$ & $\mathbf{F}$ & Sig & $\mathbf{T}$ & Df & Sig (2 tailed) \\
\hline \multicolumn{6}{|c|}{ Life Satisfaction } \\
\hline Equal variances assumed & 13.578 & 0.000 & 1.374 & 98 & 0.173 \\
\hline $\begin{array}{l}\text { Equal variances not } \\
\text { assumed }\end{array}$ & & & 1.374 & 77.982 & 0.173 \\
\hline \multicolumn{6}{|c|}{ Resilience } \\
\hline Equal variances assumed & 4.776 & 0.031 & 0.195 & 98 & 0.84 \\
\hline $\begin{array}{l}\text { Equal not variances } \\
\text { assumed }\end{array}$ & & & 0.195 & 91.976 & 0.84 \\
\hline
\end{tabular}

In table 2 it can be seen that, $\mathrm{t}$ - Test was conducted to help to understand if there were any significant differences between the means of Life Satisfaction and Resilience among parents living with their married children and not living with their married children which was found to be not significant at 0.05 level. The degree of freedom is equal to the total size of the group (100) minus 2 (98).

\section{DISCUSSION}

The aim of the present study was to understand the differences in Life Satisfaction and Resilience among parents who live with their married children and who do not live with their married children. The study hypothesized that there is a significant difference between Life Satisfaction among parents who live with their married children and who do not live with their married children.

There is a significant difference between Resilience among parents who live with their married children and who do not live with their married children. According to the results of the $t$ - Test found, no significant difference was found in the means of Life Satisfaction among parents living with their married 
children and not living with their married children. The results found that $(\mathrm{P}>0.05)$ not significant at 0.05 level. Therefore Alternate Hypothesis was not supported. Another possible reason could be area from which Parents have been chosen by the researcher seem to have affected as to there was no differentiation considered as rural or urban area. Parents were selected from various cities of Maharashtra, rural area was not selected. Another reason could be the social support, support of their friends; social networking sites and advanced technology because of which they happen to be in touch with their family members. Another possible reason could be the independent sample which consisted of 50 parents in each group, larger sample would have given the better results. Hence, one possible reason could be the facilities of policies to safeguard the future and also financial independence, because parents living with their married children usually happened to be with them for the economic conditions and financial support [17]. Studies of aging process also show people's Resilience in response to life challenges. Contrary to popular belief, most people over the age 65 are not ill- health, are not lonely, and are not suffering from depression. In fact, ratings of life satisfaction and self-esteem are, on average, as high in old age as in any other period of adulthood.

\section{REFERENCES}

1. Sudha S, Suchindran C, Mutran EJ, Rajan SI, Sarma PS. Marital status, family ties, and self-rated health among elders in South India. Journal of cross-cultural gerontology. 2006 Dec 1;21(3-4):103-20.

2. Mehrotra S, Tripathi R. Positive psychology research in India: A review and critique. J Ind Acad Appl Psychology 2011;37(1):9-26.

3. Pavot W, Diener ED, Colvin CR, Sandvik E. Further validation of the satisfaction with life scale: Evidence for the cross-method convergence of well-being measures. J Personal Assess 1991;57(1):149-61.

4. Wagnild G, Young H. Development and psychometric. J Nurs Measure 1993;1(2):165-78.

5. Richardson GE. The metatheory of resilience and resiliency. J Clin Psychol 2002;58(3):307-21.

6. Sousa L, Lyubomirsky S. Life satisfaction. Encylopedia of women and gender: Sex similarities and differences and the impact of society on gender 2001;2:667-76.

7. Bailey TC, Eng W, Frisch MB, Snyder CR. Hope and optimism as related to life satisfaction. J Positive Psychol 2007;2(3):168-75.

8. Ehrhardt JJ, Saris WE, Veenhoven R. Stability of life-satisfaction over time. J Happiness Stud 2000;1(2):177205.

9. Greene RR, Galambos C, Lee Y. Resilience theory: Theoretical and professional conceptualizations. J Hum Behav Soc Environ 2004;8(4):75-91.

10. Luthar SS. Resilience and vulnerability: Adaptation in the context of childhood adversities. Cambridge University Press; 2003.

11. Waller MA. Resilience in ecosystemic context: Evolution of the concept. Am J Orthopsychiatry 2001;71(3):290-7.

12. Masten AS. Ordinary magic: Resilience processes in development. Amer Psychologist 2001;56(3):227-38.

13. Diener ED, Emmons RA, Larsen RJ, Griffin S. The satisfaction with life scale. J Personal Assess 1985;49(1):71-5.

14. Pavot W, Diener E. Review of the satisfaction with life scale. Psychol Assess 1993;5(2):164-72.

15. Wagnild G. A review of the Resilience Scale. J Nurs Measure 2009;17(2):105-13.

16. Nishi D, Uehara R, Kondo M, Matsuoka Y. Reliability and validity of the Japanese version of the Resilience Scale and its short version. BMC Research Notes 2010;3(1):310.

17. Oishi S. The concept of life satisfaction across cultures: An IRT analysis. J Res Personality 2006;40(4):41123.

Acknowledgements - Nil

Source of Funding - Nil

Conflict of Interest - Nil 


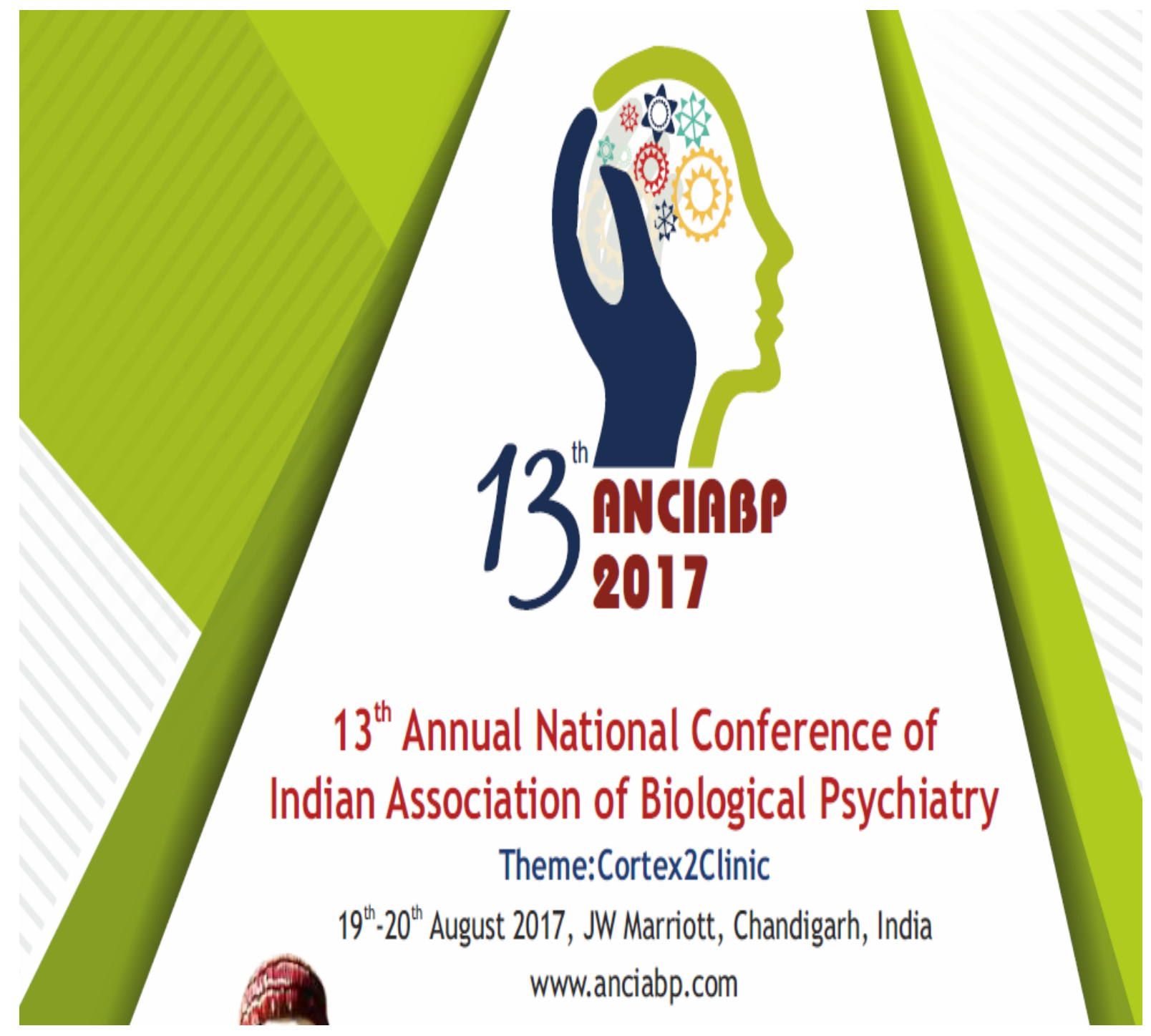

